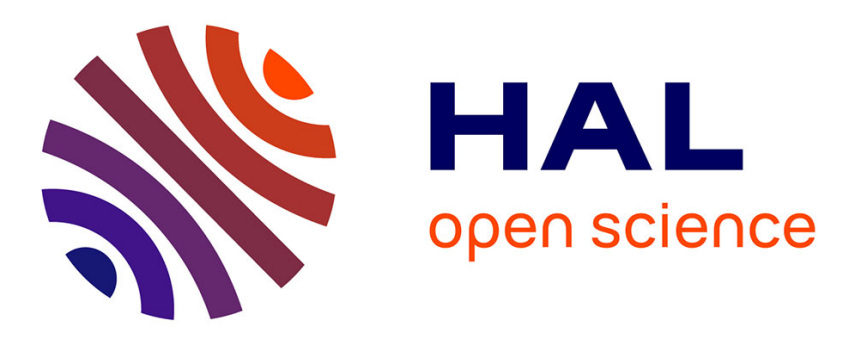

\title{
Remanufacturing as a Sustainable Strategy in Shipbuilding Industry
}

Faheem Ali, Pavan K. Sriram, Erlend Alfnes, Per Olaf Brett, Annik

Magerholm Fet

\section{> To cite this version:}

Faheem Ali, Pavan K. Sriram, Erlend Alfnes, Per Olaf Brett, Annik Magerholm Fet. Remanufacturing as a Sustainable Strategy in Shipbuilding Industry. IFIP International Conference on Advances in Production Management Systems (APMS), Sep 2015, Tokyo, Japan. pp.232-239, 10.1007/978-3-31922759-7_27. hal-01431100

\section{HAL Id: hal-01431100 https://hal.inria.fr/hal-01431100}

Submitted on 10 Jan 2017

HAL is a multi-disciplinary open access archive for the deposit and dissemination of scientific research documents, whether they are published or not. The documents may come from teaching and research institutions in France or abroad, or from public or private research centers.
L'archive ouverte pluridisciplinaire HAL, est destinée au dépôt et à la diffusion de documents scientifiques de niveau recherche, publiés ou non, émanant des établissements d'enseignement et de recherche français ou étrangers, des laboratoires publics ou privés.

\section{(c)(1)}

Distributed under a Creative Commons Attribution| 4.0 International License 


\title{
Engineer-to-Order Enabling Process: an Empirical Analysis
}

\author{
Aldo Duchi, Omid Maghazei, Davide Sili, Marco Bassan, Paul Schönsleben \\ BWI Center for Industrial Management, ETH Zürich, Zürich, Switzerland \\ \{aduchi, omaghazei\} @ethz.ch
}

\begin{abstract}
Increasing competition and fast innovation take up new challenges for engineer-to-order (ETO) companies to address special requests from customers without losing efficiency. The optimization of the trade-off between customization and operational efficiency is a core competence for ETO manufacturers. Most advanced companies are reacting by introducing an ETO Enabling Process, which is the process of transforming special requests alongside the ETO value chain into know-how to be subsequently reused with a gain in productivity. This paper, therefore, presents relevant best practices implemented within a research project with three ETO companies while adapting the ETO Enabling Process to their specific organizational settings.
\end{abstract}

Keywords: Engineer-to-Order (ETO), ETO Enabling Process, Best Practices

\section{Introduction}

Globalization, margin shrink, increased competition, delivery-time pressure and turbulent technological advances $[1,2]$ are central issues relating to the current Engineer-toOrder (ETO) environments. As a consequence, it is essential for executives to deal with such challenges in order to achieve profitable businesses. Scholars and experienced professionals put efforts to address how to react to such transformations in the competitive environment. Interestingly, they have identified a viable approach in reorganizing processes aiming at increasing operational efficiency. In this context, the introduction of product configurators is likely to optimize the trade-off between productivity and customization [3]. Along the same lines, it visualizes final product for the customer in the bidding phase and facilitates the process of quickly generating detailed drawings. Overall, this brings the possibility of efficiently programming the manufacturing machines and in turn, increases the level of automation [4].

The companies that employed the configurator in their processes, consider the 'configured' products as 'standard' products which have been produced in Make-to-Order (MTO) settings [5], despite the remarkable variety of products they are able to deliver. Although configurators have been widely examined in the past studies, recoveries in

adfa, p. 1, 2011.

(C) Springer-Verlag Berlin Heidelberg 2011 
efficiencies out of the MTO process have been largely neglected. A recent study by Schönsleben [6] indicates that advanced ETO companies are able to implement an ETO Enabling Process that is an ad-hoc process to collect and retrieve knowledge. Nonetheless, this knowledge is not entirely standardized but is sufficiently structured to be quickly retrieved. In the next sections, we introduce the ETO Enabling Process concept and we illustrate how market leaders have adopted such process out of the boundaries of the MTO process.

\section{The ETO Enabling Process}

\subsection{Redefinition of Standard and Non-Standard}

The Solution Space (SS) is a statement of all the possible permutations of design parameters that are predefined and offered to prospective customers [7]. Value creation within a finite SS is a distinctive element of ETO companies and discriminates them from conventional craft customization [8,9]. In fact, setting the appropriate SS directly affects the customer's perception of the utility of the customized product and determines the efficiency of downstream processes in the fulfillment system [10]. Advanced ETO producers are capable of representing their SS within a configurator aiming for a more efficient way of retrieval of solutions.

However, it is less likely for ETO companies to satisfy all the customers' requests just by a technical configurator and it often happens that solutions require additional manual engineering processes before being produced [11]. Schönsleben [6] claims that this kind of ETO companies have two classes of products. One is the "standard" products that can be engineered through the utilization of a configurator, and another is the "non-standard" products that call for manual processing since they have not been represented in the configurator. Also, he underlines that the "standard" solutions are developed in the context of an MTO process while "non-standards" are managed within an ETO process [12].

\subsection{ETO Enabling Process}

ETO Enabling Process "means that queries from the ongoing ETO business process are answered through a form of know-how transfer. If additional know-how is gained during implementation, it is fed back to the enabling process in the form of lessons learnt" [6]. Therefore, the ETO Enabling Process can be considered as a model for describing the way that the SS is dynamically widened in the advanced ETO companies. The ETO Enabling Process on the one hand, generates the necessary information supporting the creation of new "non-standard" solutions; on the other hand, it generates a feedback to the ETO process under the form of lesson learnt.

Each "non-standard" solution conveys, indeed, new information (the feedback of the ETO Enabling Process) that has to be adequately stored for an effective and efficient expansion of the SS. The Fig 1 shows a typical ETO business process in ETO companies (DTO stands for design-to-order which is used as a synonym of ETO). The sales phase, including quoting, is followed by the receipt of the customer's order, followed in turn by design, production and delivery [13]. We can notice that at different stages, specific requests are generated by the ETO process that must be elaborated by a parallel 
ETO Enabling Process, which in turn delivers know-how, represented by immediate solutions to the requests and permanent lessons learnt.

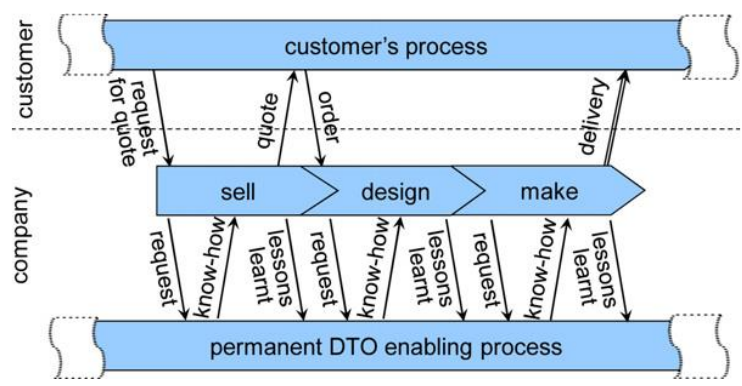

Figure 1 The ETO Enabling Process [6].

\section{$3 \quad$ Best Practices for an Effective ETO Enabling Process}

During the two years research project, in cooperation with three main industrial partners from the Swiss ETO manufacturing industries (see Table 1), various methods and tools have been developed aiming for a fast and efficient ETO process. Most notably, new reference models have been conceived and best practices have been identified. In what follows we describe the case study companies taking part in the project and we continue with the different structures of the ETO Enabling Process. Finally, a concluding table is provided to summarize the striking findings.

Table 1. Case study companies: generalizability of the results

\begin{tabular}{|l|l|l|l|}
\hline \multicolumn{1}{|c|}{ Company } & \multicolumn{1}{|c|}{ A } & \multicolumn{1}{c|}{ B } & \multicolumn{1}{c|}{ C } \\
\hline Industry & $\begin{array}{l}\text { Industrial Steam Tur- } \\
\text { bines }\end{array}$ & Elevators & $\begin{array}{l}\text { Concrete mixing and min- } \\
\text { eral processing plants }\end{array}$ \\
\hline Product & $\begin{array}{l}\text { Extremely diverse, ad } \\
\text { hoc technologies for dif- } \\
\text { ferent customer }\end{array}$ & $\begin{array}{l}\text { Slightly Diverse, high degree of } \\
\text { commonality among product } \\
\text { families }\end{array}$ & $\begin{array}{l}\text { Very Diverse, different } \\
\text { core technologies }\end{array}$ \\
\hline $\begin{array}{l}\text { Market } \\
\text { (Units/year) }\end{array}$ & Less than 50 & More than 1000 & $300-500$ \\
\hline $\begin{array}{l}\text { Supporting } \\
\text { IT Systems }\end{array}$ & Sales Configurator & Design Configurator & Design Configurator \\
\hline
\end{tabular}

The best practices that are presented in this paper are aligned with the use of configurator. Depending on the need of the company, the configurator can be used in different phases of the solution delivery: if it is utilized in the design phase, it will be a technical configurator; otherwise if it is used only as a support for the bidding phase, it will be a sales configurator [14].

\subsection{Company A}

Company A is a large multinational enterprise, which operates in the power generation sector. The division collaborating in the research project is offering power steam tur- 
bines units. The business unit counts approximately 120 engineers placed in three different European countries. The unit, appointed to realize order specific engineering, accounts only for a small percentage (less than 5\%) of the total turnover of the company, but is on rapid expansion.

More than the $70 \%$ of the total lead time to deliver a product is due to the engineering purposes. The high diversity in terms of technology and functionalities leads to more than 5000 man-hours of engineering on average to complete a project. In fact, an engineering project is divided into subtasks that each of them refers to a specific component for the product.

Being the business unit at a low maturity stage, the utilization of the configurator is limited only to the sales phase. For what concerns the technical configuration, Company A has employed a "configuration matrix", collecting the rule of association between a few modules they have already developed. Therefore, the ETO Enabling Process for this kind of company is mainly settled to the quick retrieval of product-related information. This is achieved both through the creation of ad-hoc repositories and through the introduction of search functions fulfilled to navigate through the company's SS. In the following the company's tailored solutions have been introduced accordingly.

Naming Convention: naming convention provides a common language protocol for the product. The naming convention allows to rapidly gather relevant engineering related information like the position in the work breakdown structure (WBS), the type, the material and/or any other special attributes. Naming Convention plays a vital role in the Company A's ETO Enabling Process because when new requests are coming to the engineering stage, the process of retrieval is therefore, facilitated with substantial savings in time and cost.

Order execution configurator: this tool is utilized to acquire more information about product subassemblies and components. This information might be both technical (past drawings) and process related (list of suppliers or internal manufacturers). By filling in a small set of parameters it is, therefore, possible to find a component which is the most similar to the special request entered in the ETO process. Thus, this tool yields considerable benefits in compressing the time needed to develop customer-specific solutions.

Documentation Sharing Platform: it is a platform for the storage and sharing of documentations between the company and its suppliers/customers. One advantage is related to the storage and retrieval of old documentations. For instance, if the post-sales services are delivered many years after the delivery of the order, it provides an effective process to retrieve documents instead of having these documents stored in scattered email archives. A second advantage is the greater visibility over the documentation exchange process.

\subsection{Company B}

Company B is among the worldwide leaders in design, engineering, manufacturing and maintaining of freight and special elevators. The research project was conducted with the division offering high-rise elevators. The investigated business unit has more than 200 employees and acts in two different locations, in Europe and in the Asia-Pacific Area, with the $75 \%$ of the total of the realized projects. The investigated division is 
appointed to realize order specific engineering for customers' specifications and offering support to the sales manager. This division is attached to the technical direction of the group. A remarkable point is that the level of knowledge in the two locations is significantly different. The reason is that despite several years of trainings and group works, most of the advanced technologies and know-how are kept by the European site. In terms of standardization, its level appears markedly high, with a considerable amount of projects designed and realized entirely within the technical configurator. The configurator has showed a great level of flexibility through the adoption of parametric product families. It is made possible by the high volume of specifications sold per year, which allows to identify communalities in the requests of customers and in turn to include new requests into the configurator.

Company B is at a mature stage, additionally its products can be considered of lower complexity compared with the two other companies. For this reason this company owes an especial configurator which is, at the same time, a sales and a technical configurator. Therefore, the ETO process at Company B is extremely advanced and a large portion of the company's product variance can be managed within an MTO process. Nonetheless, when non-standard boundary is extremely far from the company's SS, engineers are obliged to intervene with manual calculations and drawings. The following methods and tools have been applied to structure the ETO Enabling Process at Company B.

AE-PLM Process: Application Engineering (AE) is the office at Company B responsible for the execution of non-standard orders and it is the owner of the ETO Enabling Process as the source of know-how for non-standard requests. Product Line Management (PLM), owners of the product lines, also contributes to the ETO Enabling Process as it retains the modification rights in the configurator. AE and PLM are periodically (6 months) called to collaborate and modify the configurator so that it continuously incorporates previously developed non-standard solutions. In order to optimize this process, Company B decided to formalize it. This process can be considered as a part of the ETO Enabling Process.

Frequently Asked Request Tool: The FAR (Frequently Asked Requests) tool purpose is to support Application Engineers in the identification of incoming frequent tasks. Frequent tasks are often related to the same violation in the configuration parameters (each of the configuration parameters is laying in a certain range). Therefore, by identifying frequent tasks, we obtain a rule for the modification to be applied to the configurator. The FAR Tool is used at a very early stages of the AE-PLM Process. This is an extremely advanced setting of the ETO Enabling Process, because it drives the automation to the processes related to the less standardized part of its SS.

SE-AE Process: Sales Engineering (SE) is responsible for the MTO process at Company $\mathrm{B}$. When they are not able to deal with the requests within the configurator, they ask for the assistance of AE. SE gives engineering tasks as inputs to $\mathrm{AE}$ and receives, as outputs, solutions to non-standard related issues. In this process, it also automatically transfers the list of all the parameter range violation (list of deviations). In the past, SE had to manually fill in the information related to the engineering tasks, this brought to incompleteness or low quality of input data for AE. Applying automation in the process of creation of engineering tasks increases efficiency of the ETO Enabling Process. 


\subsection{Company $\mathrm{C}$}

Company $\mathrm{C}$ is a manufacturer of asphalt mixing, concrete mixing and mineral processing plant. A tailored business unit is appointed to manage the concrete mixing plants. This includes a division taking care of operations (production), planning and engineering, a dedicated commercial unit for sales and a key account manager. It is worth mentioning that the design is taking place in three different engineering locations.

Even if the knowledge base is already widely developed, Company C's ETO Enabling Process has not already been fully developed. The extreme engineering complexity has prevented the company from reaching the same degrees of standardization as observed at Company B. Nonetheless, the company is introducing new tools and processes, aiming at reducing the amount of redundancy in operations thanks to the accumulation and use of past knowledge and experience.

Task Manager: in order to avoid inefficient recycles in the ETO process the company has designed a Task Management System. Whenever an issue emerges at each stage, a solution to the request must be immediately provided by the technical office. Nonetheless, at Company C, despite the fact that the reaction to the emergent requests is effective and efficient, the reoccurrence of the same request is a waste of resources. For example, if an error in production happened because of a mistake in the drawings and these are not permanently modified, there is the possibility that the same error will take place again. The Task Manager is also, a supporting tool for successful execution of the ETO Enabling Process. The Task Manager enables the possibility for the company to turn project-specific requests into knowledge (e.g. fixed drawings) used to avoid wasteful recycles.

Sharing Platform: The three main engineering locations are able to engineer the whole product mix offered by the company, even if they serve different markets. It is likely to happen that the two locations respond to similar requests from the customers. Subsequently, a low degree of knowledge sharing brings significant wastes in the time spent in engineering phase since it is likely that the same issues are solved twice. In order to avoid the inefficiencies deriving from low communications, the company has decided to develop a Sharing Platform in its business intranet. Hence, engineers at each location can rapidly apprised of the configurations developed in the other locations. The platform is also a communication tool, but it primarily is a knowledge repository where special requests are transformed into valuable knowledge for the whole company. This sharing platform is an interesting example because, it transforms requests into knowledge not only to transfer them, but also to reuse them in the future projects.

\subsection{Summary}

On the one hand, some of the aforementioned best practices (AE-PLM Process, Documentation Sharing Platform, SE-AE Process and the Task Manager) support fluent information flow between different actors. In addition, they stimulate the standardization of the information exchange that eventually make it less dependent on the key actors. On the other hand, other best practices such as the Order Execution Configurator, the FAR Tool and the Sharing Platform, are information repository tools that create reusable knowledge. Moreover, this knowledge creation leads to shrink the non-standard solution space and in turn, offers more degrees of customization. 
Table 2. Best practices summary

\begin{tabular}{|c|c|c|}
\hline & Enabling process & Description \\
\hline \multirow{3}{*}{ 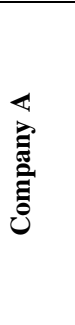 } & Naming Convention & $\begin{array}{l}\text { A new naming convention has been developed in order to create a ref- } \\
\text { erence language within the company for the identification of products, } \\
\text { sub-assemblies and components. }\end{array}$ \\
\hline & $\begin{array}{l}\text { Order Execution Con- } \\
\text { figurator }\end{array}$ & $\begin{array}{l}\text { Dynamic Design Containers have been established. Design Containers } \\
\text { function as maps for the retrieval of the relevant historical information } \\
\text { related to the product parts. }\end{array}$ \\
\hline & $\begin{array}{l}\text { Documentation Shar- } \\
\text { ing Platform }\end{array}$ & $\begin{array}{l}\text { A documentation sharing platform has been implemented. The objec- } \\
\text { tive of this platform is to create a single point of contact between the } \\
\text { company and its customers/suppliers and to have a unique repository } \\
\text { for relevant documentation (no dispersion in several mail boxes). }\end{array}$ \\
\hline \multirow{3}{*}{ 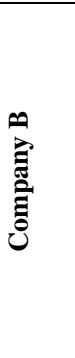 } & AE-PLM process & $\begin{array}{l}\text { The interface between AE (Application Engineering) process and PLM } \\
\text { (Product Line Management) process has been defined. A detailed defi- } \\
\text { nition of this interface was necessary to guarantee a rapid and accurate } \\
\text { execution of new releases of the product configurator. }\end{array}$ \\
\hline & FAR Tool & $\begin{array}{l}\text { An FAR (Frequently Asked Request) tool has been developed in Visual } \\
\text { Basic in order to extrapolate relevant statistics related to the requests in } \\
\text { order to identify the most common ones. }\end{array}$ \\
\hline & SE-AE Process & $\begin{array}{l}\text { The exchange of relevant information between the Sales Engineering } \\
\text { and Application Engineering offices has been automatized. In particu- } \\
\text { lar, the system has been modified to feed in automatically necessary in- } \\
\text { formation during the phase of generation of new engineering requests. }\end{array}$ \\
\hline \multirow{2}{*}{$\dot{\Xi}$} & Task Manager & $\begin{array}{l}\text { A task management system has been designed in order to guarantee a } \\
\text { permanent solution of the engineering related issues. }\end{array}$ \\
\hline & Sharing Platform & $\begin{array}{l}\text { A repository for sharing new engineering solutions between different } \\
\text { engineering locations has been designed. }\end{array}$ \\
\hline
\end{tabular}

\section{Conclusions}

The challenge for ETO companies is still the tradeoff between customization and operational efficiency. In order to counterbalance the tradeoff, we present results in terms of best practices to achieve efficiency in the ETO process, which have been explored in the research project with three industrial partners. As a know-how transferring process, it represents for companies a long-term key strategy that aims to reduce the degrees of uncertainty in ETO environment. Thus, through the adoption of the right tools, the companies aimed to extend the predefined solution space by integrating order specific solutions, making them reusable for future projects, and eventually increasing standardization. Additionally, those practices turn out to reduce the degrees of uncertainty and complexity in an ETO environment that is by definition, subject of constant changes.

Each company involved in the project has focused their efforts on the solutions that better fit their products, markets and organizational structures. Company A had to bring to light hidden processes and knowledge that were embedded to the individuals and are spread in the dispersed repositories. The ETO process of company B is taking place in different countries. Consequently, the main improvements of Company B were in light of standardizing the communications and sharing processes. For company $\mathrm{C}$, whose engineering business function is spanning in three different locations, the focus was on facilitating the communication process between the locations, establishing a framework to standardize the outputs, and to share the locally discovered solutions.

Depending on the degrees of similarity with the three project companies that have 
successfully implemented the practices, other ETO companies are likely to duplicate the practiced tools to achieve higher performances in terms of uncertainty and complexity reduction. This study opens up new avenues for exploring a proper taxonomy of the ETO environment in order to effectively bring companies' characteristics and the best practices together.

Acknowledgments. This work is funded by the research project through the Swiss Commission for Technology and Innovation CTI (CTI no.: 15021.1 PFES-ES). The authors would like to thank all participating organizations for sharing their insights in the ETO industry.

\section{References}

1. S. Kumar and J. Wellbrock, "Improved new product development through enhanced design architecture for engineer-to-order companies," Int. J. Prod. Res., vol. 47, no. 15, pp. 4235-4254, Aug. 2009.

2. A. Pandit and Y. Zhu, "An ontology-based approach to support decision-making for the design of ETO (Engineer-To-Order) products," Autom. Constr., vol. 16, no. 6, pp. 759770, Sep. 2007.

3. C. Forza and F. Salvador, "Managing for variety in the order acquisition and fulfilment process: The contribution of product configuration systems," Int. J. Prod. Econ., vol. 76, no. 1, pp. 87-98, 2002.

4. B. Sjøbakk, M. Thomassen, and E. Alfnes, "Implications of automation in engineer-to-order production: a case study," Adv. Manuf., 2014.

5. Wikner, Joakim, and Martin Rudberg. "Integrating production and engineering perspectives on the customer order decoupling point." International Journal of Operations \& Production Management 25, no. 7, pp. 623-641, 2005.

6. P. Schönsleben, "Methods and tools that support a fast and efficient Engineer-to-Order process for parameterized product families," CIRP Ann. Technol., 2012.

7. I. B. J. Pine, Mass customization: the new frontier in business competition. 1999.

8. J. Lampel and H. Mintzberg, "Customizing Customization.," Sloan Manage. Rev., vol. 38, no. 1, pp. 21-30, 1996.

9. D. Robertson and K. Ulrich, "Planning for Product Platforms," Sloan Manag. Rev., vol. 39, no. 4, pp. 19-31, 1998.

10. M. Tseng and F. T. Piller, "The customer centric enterprise," in Customer Centric Enterprise: Advances in Mass Customization and Personalization, pp. 3-16, 2003.

11. A. Haug, K. Ladeby, and K. Edwards, "From engineer-to-order to mass customization," Manag. Res. News, vol. 32, no. 7, pp. 633-644, 2009.

12. O. Willner, D. Powell, A. Duchi, and P. Schönsleben, "Globally distributed engineering processes: Making the distinction between engineer-To-order and make-To-order," in Procedia CIRP, 2014, vol. 17, pp. 663-668.

13. Willner, Olga, Manuel Rippel, Matthias Wandfluh, and Paul Schönsleben. "Development of a Business Process Matrix for Structuring the Implications of Using Configurators in an Engineer-To-Order Environment." In APMS, 2013.

14. M. Mäkipää, P. Paunu, and T. Ingalsuo, "Utilization of Design Configurators in Order Engineering,” Int. J. Ind. Eng. Manag., vol. 3, no. 4, pp. 223-231, 2012. 